\title{
PENGGUNAAN MEDIA AUDIO, VISUAL, DAN AUDIOVISUAL DALAM MENINGKATKAN PEMBELAJARAN KEPADA GURU-GURU
}

\author{
Iis Dewi Lestari ${ }^{1}$ Halimatusha'diah ${ }^{2}$ Fibria Anggraini Puji Lestari ${ }^{3}$ \\ Program Studi Informatika, FTMIPA, Universitas Indraprasta PGRI \\ iisdewi_lestari@yahoo.co.id ${ }^{1}$, halimah3186@gmail.com $^{2}$, fapl02@yahoo.com $^{3}$
}

\begin{abstract}
Abstrak
Kegiatan ini bertujuan untuk memberikan pemahaman kepada guru-guru tentang pentingnya penggunaan media audio, visual, dan audiovisual untuk meningkatkan efektivitas pembelajaran di kelas. Target luaran kegiatan ini adalah 1) guru-guru dapat memahami pentingnya penggunaan media audio, visual, dan audiovisual untuk meningkatkan kualitas pembelajaran, 2) memberikan beberapa alternative kepada guru dalam penggunaan media pembelajaran, 3) guru-guru dapat menggunakan ragam media audio, visual, dan audiovisual dalam proses pembelajaran di kelas. Kegiatan sosialisasi dilakukan kepada guru-guru di SDN RRI Nasional dan SDN Mekarjaya 30, Depok. Metode yang digunakan dalam kegiatan sosialisasi ini adalah diskusi, tanya jawab, dan simulasi hasil sosialisasi. Tahapan-tahapan yang dilakukan dalam kegiatan ini adalah 1) observasi lapangan 2) pengenalan dan sosialisasi, 3) implementasi hasil sosialisasi. Kesimpulan dari hasil sosialisasi ini adalah 1) perlu dilakukannya pelatihan-pelatihan secara berkelanjutan dalam hal penggunaan media dan penyiapan materi ajar dalam bentuk audio, visual, dan audiovisual bagi para guru, 2) perlu tersedianya referensi bahan ajar yang memadai untuk menunjang pembelajaran dengan menggunakan media audio, visual, dan audiovisual.
\end{abstract}

Kata Kunci: Media audio, visual, audiovisual; Pembelajaran

\begin{abstract}
This activity aims to provide understanding to teachers about the importance of using audio, visual, and audiovisual media to improve the effectiveness of learning in the classroom. Output targets of this activity are 1) teachers can understand the importance of using audio, visual, and audiovisual media to improve the quality of learning, 2) provide some alternative to teachers in using learning media, 3) teachers can use various audio, visual, and audiovisual media in the process of learning in the classroom. The socialization was conducted for teachers at SDN RRI Nasional and SDN Mekarjaya 30, Depok. The methods used in this socialization are discussion, question and answer, and simulation. The steps undertaken in this activity are 1) field observation 2) introduction and socialization, 3) implementation of socialization result. The conclusions of the results of this socialization are 1) the need for continuous training in the use of media and the preparation of teaching materials in the form of audio, visual, and audiovisual for the teachers, 2) the need for adequate reference of teaching materials to support the learning by using audio, visual, and audiovisual media.
\end{abstract}

Keywords: Audio, visual, and audiovisual media; Learning 


\section{PENDAHULUAN}

Strategi pembelajaran adalah suatu kegiatan pembelajaran yang harus dikerjakan guru dan peserta didik agar tujuan pembelajaran tercapai. Millan menyatakan, Teaching is a process of effective decision making. This includes deciding what to teach, how to teach it, how long to teach, whether to group students, what questions to ask, what follow up questions to ask, what to review and so forth (Millan, 2008:5). Dengan demikian, strategi pembelajaran hendaknya ditunjang dengan media pembelajaran yang mumpuni.

Ketika teknologi khususnya teknologi informasi belum berkembang seperti saat ini, proses pembelajaran hanya tergantung pada waktu dan tempat tertentu. Proses pembelajaran sangat tergantung pada guru sebagai sumber belajar. Media pembelajaran adalah seluruh alat dan bahan yang dapat dipakai untuk tujuan pendidikan seperti radio, televisi, buku, koran, majalah dan sebagainya. Penggunaan media pembelajaran tidak sekedar menggunakan media dalam proses pembelajaran tanpa pertimbangan maupun perencanaan yang matang. Prinsip yang mendasar dalam penggunaan media ini adalah kesederhanaan, tekanan penjelasan dan keterbacaan.

Prinsip penggunaan media menurut Sanjaya adalah prinsip kesesuaian, efektivitas dan efisiensi dan keterjangkauan. Prinsip kesesuaian dapat dijabarkan bahwa penggunaan media harus disesuaikan dengan tujuan pembelajaran, materi, minat, kebutuhan, dan kondisi peserta didik. Teknologi dan media memiliki peran penting yang banyak dalam pembelajaran tergantung pada kebutuhannya. Pada satu saat media bisa membantu guru dalam mentransfer konsep pembelajaran. Pada saat yang lain media bisa digunakan sebagai pengganti guru.

Media visual juga bisa disebut sebagai media pandang karena seseorang dapat memahami media yang disajikan melalui penglihatan. Menurut Anitah, media gambar yang diterapkan dalam pembelajaran memiliki manfaat antara lain menimbulkan daya tarik bagi pembelajar, mempermudah pengertian dan pemahaman pembelajar, memperjelas bagian-bagian penting dalam pembelajaran, dan menyingkat suatu uraian yang panjang (Anitah, 2011:9). Media audio menurut Sanjaya (2010:172) adalah media yang hanya dapat didengar saja atau dengan kata lain hanya memiliki unsur suara. Seperti radio, kaset, telepon, dan rekaman suara. Media audiovisual menyatakan seperangkat alat yang dapat memproyeksikan ganbar bergerak dan bersuara, alatalat tersebut seperti televisi, PC-speaker active, VCD dan media sound slide (Sanaky, 2011:105).

Proses pembelajaran di kelas berada pada empat variabel interaksi yaitu variabel pertanda berupa pendidik, variabel konteks berupa peserta didik, sekolah dan masyarakat, variabel proses berupa interaksi peserta didik dengan pendidik dan variabel produk berupa perkembangan peserta didik dalam jangka pendek maupun panjang, (Syaiful: 2012: 61).

SDN Mekarjaya 30 dan RRI Nasional merupakan sekolah dengan peserta didik dan guru yang cukup banyak di kota Depok. Kedua sekolah tersebut menjadi sekolah yang dapat bersaing dengan sekolah-sekolah lain di Kota Depok. Dengan identitas sekolah yang cukup ternama dan jumlah warga sekolah yang banyak, memunculkan keinginan untuk meningkatkan kualitas pembelajaran bagi guru-guru di sekolah tersebut dengan memberikan sosialisasi penggunaan media audio, visual dan 
audiovisual dalam pembelajaran. Hal ini didasarkan pada hasil observasi bahwa masih banyak guru di kedua sekolah tersebut yang belum bisa menguasai atau menggunakan media tersebut, penggunaan metode ajar juga masih monoton, yaitu hanya menggunakan metode ceramah dengan media papan tulis dan buku ajar. Apabila seluruh guru dapat menggunakan media pembelajaran audio, visual, dan audiovisual secara lebih efektif, maka diharapkan sekolah tersebut akan semakin maju dengan mengikuti perkembangan teknologi dan informasi dalam pembelajaran. Peserta didik akan semangat dalam proses pembelajarannya, begitu pun dengan guru, diharapkan dapat meningkatkan kreatifitas dan inovasi untuk menggunakan media audio, visual, dan audiovisual dalam pembelajaran di kelas.

\section{Target dan Luaran}

Guru harus memiliki empat kompetensi yaitu pedagogik, profesional, kepribadian dan sosial. Keempat kompetensi ini merupakan bagian integral yang tidak dapat dipisahkan bagi guru dalam melaksanakan tugas dan kewajibannya sebagai pendidik. Selvi mengatakan teachers competencies affect their values, behaviors, communication, aims and practice in school and also they support professional development and curricural studies. Thus, the discussion on teachers competencieis to improve the teachinglearning process in school is of great importance (Selvi, 2010: 7). Guru sebenarnya memiliki kewenangan yang sangat besar dalam proses pembelajaran, baik dalam hal persiapan, pelaksanaan, evaluasi maupun pengambilan keputusan penilaian. Kemampuan pengembangan pembelajaran mutlak juga harus dimiliki oleh guru, diharapkan guru mampu menghasilkan inovasi dalam pembelajaran untuk meningkatkan kualitas pembelajaran di kelas. Proses pembelajaran pada hakikatnya adalah komunikasi dimana guru sebagai pengantar pesan dan peserta didik sebagai penerima pesan. Penggunaan media audio, visual dan audiovisual sangat membantu guru dalam proses pembelajaran. Peserta didik akan jauh lebih semangat dalam menerima materi yang disampaikan oleh guru. Sedangkan guru, juga dituntut untuk lebih mengembangkan keahlian, profesionalitas dalam meningkatkan kualitas pembelajaran di kelas melalui penggunaan ragam media pembelajaran audio, visual dan audiovisual.

Jenis luaran yang dihasilkan dalam pengabdian ini adalah guru-guru dapat menggunakan ragam media audio, visual dan audiovisual dalam pembelajaran di kelas untuk meningkatkan kualitas pendidikan dan kemajuan sekolah. Hal ini bisa dilakukan dengan dukungan dari kepala sekolah, sarana dan prasarana yang tersedia di sekolah. Dukungan dari sesama guru untuk mengembangkan ragam media pembelajaran di kelas tiap harinya. Dengan penggunaan media yang bervariasi akan menumbuhkan semangat belajar yang tinggi bagi peserta didik. Selain itu, guru pun akan semakin mengikuti perkembangan zaman, kemajuan informasi dan teknologi. Guru pun akan jauh lebih berkualitas dan kreatif dalam proses pembelajaran di kelas.

Penggunaan media audio, visual dan audiovisual tidak hanya diberlakukan bagi kelas 4, 5, dan 6 saja. Hal ini dikarenakan kurangnya keahlian guru untuk menggunakan media audiovisual di kelas 1, 2, dan 3. Setelah melakukan sosialisasi ini diharapkan seluruh guru yang mengajar di sekolah tersebut dapat menggunakan media audio, visual dan audiovisual. Meskipun kendalanya adalah kurangnya sarana di sekolah yang 
sangat terbatas sehingga harus bergantian jika ingin menggunakan media audiovisual. Disisi lain peserta didik justru lebih tertarik dan bersemangat jika seorang guru menyampaikan materi melalui media audiovisual.

\section{METODE PELAKSANAAN}

Kegiatan sosialisasi penggunaan media audio, visual, dan audiovisual dilaksanakan di SDN Mekarjaya 30 dan RRI Nasional di Depok terhadap guruguru. Kegiatan pengabdian ini dilakukan dengan metode diskusi, tanya jawab, dan simulasi hasil sosialisasi oleh guru.

\section{Tahapan Pelaksanaan}

Kegiatan pengabdian dilaksanakan pada bulan Maret 2017 s.d. Juli 2017 dengan tahapan pelaksanaan kegiatan adalah sebagai berikut:

1. Mengadakan observasi ke SDN Mekarjaya 30 dan RRI Nasional Depok untuk melihat proses pembelajaran di kelas dan kegiatan yang dilakukan guru baik di dalam kelas maupun di luar kelas sebagai penunjang untuk melakukan pengabdian masyarakat yang kami lakukan.

2. Mengenalkan kepada guru-guru tentang pentingnya penggunaan media audio, visual dan audiovisual dalam pembelajaran di kelas.

3. Melakukan sosialisasi kepada guruguru untuk menggunakan media dalam pembelajaran di kelas.

4. Memberikan kesempatan kepada guru-guru untuk mengimplementasikan hasil dari sosialisasi yang telah dilakukan.

\section{Pelaksanaan Kegiatan}

Kegiatan sosialisasi dilaksanakan atas dasar perizinan dari pihak sekolah, yaitu SDN Mekarjaya 30 dan SDN RRI Nasional. Kegiatan sosialisasi ini diawali dengan observasi lapangan untuk mengetahui kondisi sekolah dan proses pembelajaran oleh guru di kelas. Hal tersebut dimaksudkan agar pelaksanaan kegiatan sosialisasi dapat disesuaikan dengan kondisi belajar, guru, jadwal, dan fasilitas yang ada di sekolah. Hasil observasi yang dilakukan, diketahui beberapa guru sudah mulai menggunakan media audio, visual, dan audiovisual, dan sebagian besar lainnya masih belum menggunakan media tersebut secara optimal.

Kegiatan selanjutnya yaitu melakukan pengenalan dan sosialisasi kepada guru-guru tentang pentingnya penggunaan media video, visual, dan audiovisual dalam pembelajara di kelas. Pengenalan ini dilakukan melalui metode diskusi dan tanya jawab kepada para guru. Dalam tahapan ini, guru-guru menceritakan pengalaman mengajarnya dengan media yang mereka gunakan. Sebagian besar guru di dua sekolah tersebut mengajar dengan media seadanya, seperti papan tulis dan buku ajar. Adapun media lain yang digunakan adalah proyektor untuk menampilkan video atau presentasi dalam bentuk powerpoint, namun penggunaannya tidak berkelanjutan, dan hanya digunakan pada materi-materi tertentu. Kendala-kendala yang dirasakan oleh guru beranekaragam, diantaranya kurangnya kemampuan dalam mengoperasikan media audiovisual, seperti proyektor; kurangnya kreativitas guru dalam menggunakan media audiovisual; dan penyesuaian guru terhadap materi kurikulum 2013 yang menjadikan guru kesulitan mengaplikasikan materi ke dalam media audiovisual.

Berdasarkan hasil pengenalan dan sosialisasi yang telah dilakukan kepada guru-guru di sekolah, maka dilakukan simulasi pembelajaran dengan menggunakan media audio, visual, dan audiovisual oleh guru kepada peserta 
didik. Dari masing-masing sekolah, ditunjuk satu guru untuk melakukan praktik mengajar dengan menggunakan media-media tersebut. Hasil simulasi terhadap peserta didik menunjukkan

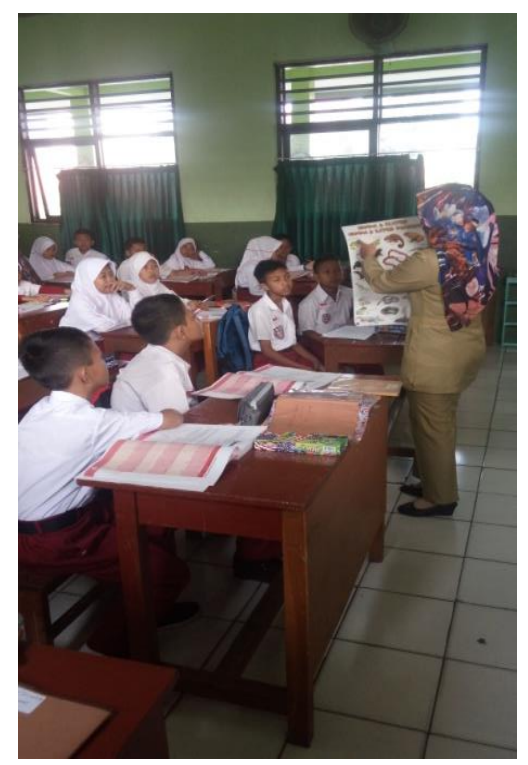

Gambar 1. Simulasi terhadap peserta didik oleh guru SDN Mekarjaya 30

\section{HASIL DAN PEMBAHASAN}

Kegiatan sosialisasi penggunaan media audio, visual, dan audiovisual telah dilaksanakan di SDN Mekarjaya 30 dan SDN RRI Nasional, yang dilakukan oleh Tim Pengabdian Masyarakat dari Universitas Indraprasta PGRI yang beranggotakan 3 (tiga) orang. Kegiatan dilaksanakan terhadap guru di ruang guru dan ruang kelas.

Kegiatan ini diawali dengan observasi dua mitra tersebut pada bulan April 2017 untuk mengumpulkan informasi, menganalisis masalah dan mengidentifikasikan segala yang berkaitan dengan guru dan penggunaan media pembelajaran khususnya audio, visual dan audiovisual. Di bulan MeiJuni, para pengabdi melakukan pengumpulan berbagai media pembelajaran untuk memudahkan dalam kegiatan sosialisasi pada guru-guru. Pada bulan antusiasme peserta didik yang lebih tinggi terhadap materi ajar karena materi yang disampaikan oleh guru lebih mudah dipahami dengan bantuan media audio, visual, dan audiovisual tersebut.

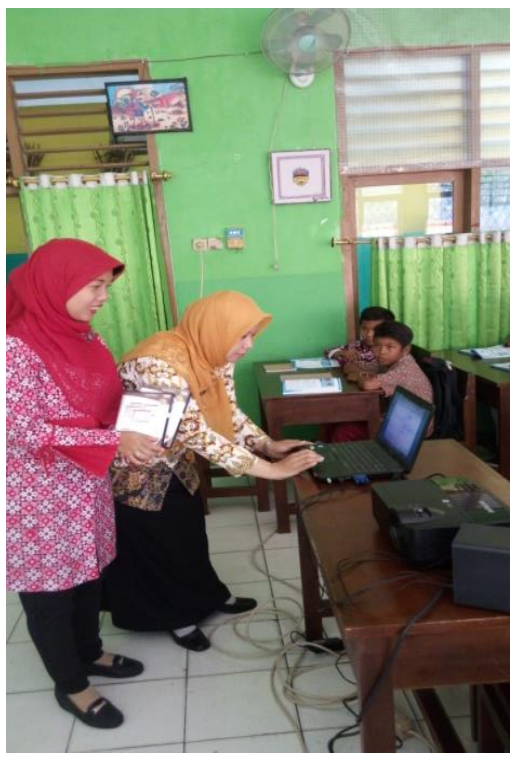

Gambar 2. Simulasi terhadap peserta didik oleh guru SDN RRI Nasional

Juli 2017melakukan kegiatan sosialisasi penggunaan media audio, visual dan audiovisual kepada guru-guru yang dilakukan di ruang guru dengan metode diskusi. Dari hasil sosialisasi kepada guru-guru dapat diketahui bahwa tidak semua guru dapat mengoperasionalkan media audiovisual dan keterbatasan sarana dan prasarana yang ada di sekolah kurang mendukung. Guru-guru lebih banyak menggunakan media visual yang mudah didapat dan terjangkau dalam proses pembelajaran. Pada bulan Agustus 2017, guru-guru mulai mengimplementasikan media audiovisual ketika proses pembelajaran di kelas. Hanya guru di kelas 4,5 dan 6 saja yang dapat menggunakan media audiovisual karena keterbatasan sarana dan disesuaikan dengan materi dan bahan ajar yang dimiliki guru.

Berdasarkan sosialisasi yang telah dilakukan, diperoleh hasil sebagai 
berikut: 1) Guru antusias untuk mencoba mengaplikasikan materi ke dalam media audio, visual, dan audiovisual; 2) Guru memahami cara mengoperasikan media audio, visual, dan audiovisual; 3) Guru mendapatkan alternatif bahan ajar untuk diaplikasikan ke dalam media audio, visual, dan audiovisual dalam pembelajaran di kelas.

\section{SIMPULAN}

Sosialisasi penggunaan media audio, visual, dan audiovisual terhadap guru-guru di SDN Mekarjaya 30 dan SDN RRI Nasional, Kota Depok, telah dilakukan dengan tahapan pelaksanaan yang meliputi observasi, pengenalan, sosialisasi, dan implementasi (simulasi) hasil sosialisasi. Berdasarkan hasil sosialisasi yang telah dilakukan, diketahui bahwa kegiatan ini sangat relevan dengan kebutuhan pembelajaran di era teknologi komunikasi dan informasi saat ini. Penggunaan media pembelajaran yang lebih kreatif dan menarik memudahkan peserta didik dalam memahami materi yang disampaikan oleh guru. Tentunya hal ini perlu diiringi dengan kemampuan guru dalam menggunakan, mengoperasikan, dan mengaplikasikan materi ajar ke dalam media audi, visual, dan audiovisual, serta didukung oleh fasilitas dan referensi bahan ajar yang memadai.

Mengingat peningkatan kemampuan menggunakan media audio, visual, dan audiovisual membutuhkan waktu dan pelatihan yang intensif, maka dibutuhkan dukungan dari berbagai pihak terkait, termasuk sekolah, gugus, dan dinas pendidikan setempat untuk dapat menyediakan dan memfasilitasi pelatihan-pelatihan dan bahan ajar tambahan dengan media audio, visual, dan audiovisual untuk para guru.

\section{DAFTAR PUSTAKA}

Anitah, S. (2011). Media Pembelajaran. Surakarta: UNS Press

James H.M.M. (2008). Assesment Essentials for Standars Based Education. Singapore: Corwin Press.

Sagala, S. (2012). Konsep dan Makna Pembelajaran, Bandung: Alfabeta

Sanaky, H. (2011). Media Pembelajaran. Yogyakarta: Kaukaba Dipantara

Selvi, K. (2010). Teachers' competencies. Journal of Philosophy of Culture and Axiology.7, 1-10

Sigit, M. (2013). Pembelajaran Berbasis Riset. Jakarta: Akademia

Wina, S. (2013). Perencanaan dan Desain Sistem Pembelajaran, Jakarta: Kencana Prenadamedia Group. 